\title{
Modeling and Analysis of Mechanical Properties of Aluminium Alloy (A413) Processed through Squeeze Casting Route Using Artificial Neural Network Model and Statistical Technique
}

\author{
R. Soundararajan, ${ }^{1}$ A. Ramesh, ${ }^{2}$ S. Sivasankaran, ${ }^{3}$ and A. Sathishkumar ${ }^{4}$ \\ ${ }^{1}$ Department of Mechanical Engineering, Sri Krishna College of Engineering \& Technology, Coimbatore 640008, India \\ ${ }^{2}$ Department of Mechanical Engineering, Sri Krishna College of Technology, Coimbatore 641042, India \\ ${ }^{3}$ School of Mechanical and Electromechanical Engineering, Institute of Technology, Hawassa University, 1530 Awassa, Ethiopia \\ ${ }^{4}$ Department of Mechanical Engineering, PPG Institute of Technology, Coimbatore 641035, India \\ Correspondence should be addressed to R. Soundararajan; soundararajan.mtech@gmail.com
}

Received 7 April 2015; Revised 1 July 2015; Accepted 6 July 2015

Academic Editor: Wei Zhou

Copyright (C) 2015 R. Soundararajan et al. This is an open access article distributed under the Creative Commons Attribution License, which permits unrestricted use, distribution, and reproduction in any medium, provided the original work is properly cited.

Artificial Neural Network (ANN) approach was used for predicting and analyzing the mechanical properties of A413 aluminum alloy produced by squeeze casting route. The experiments are carried out with different controlled input variables such as squeeze pressure, die preheating temperature, and melt temperature as per Full Factorial Design (FFD). The accounted absolute process variables produce a casting with pore-free and ideal fine grain dendritic structure resulting in good mechanical properties such as hardness, ultimate tensile strength, and yield strength. As a primary objective, a feed forward back propagation ANN model has been developed with different architectures for ensuring the definiteness of the values. The developed model along with its predicted data was in good agreement with the experimental data, inferring the valuable performance of the optimal model. From the work it was ascertained that, for castings produced by squeeze casting route, the ANN is an alternative method for predicting the mechanical properties and appropriate results can be estimated rather than measured, thereby reducing the testing time and cost. As a secondary objective, quantitative and statistical analysis was performed in order to evaluate the effect of process parameters on the mechanical properties of the castings.

\section{Introduction}

The automobile industries are focusing their concentration on light weight vehicles due to market demand and governing regulations. Weight reduction in vehicles can be achieved by new engineering design and application of lightweight materials such as aluminium alloys and magnesium alloys. Among the lightweight materials a large amount of castings are made from Al-Si alloys. This alloy is one of the most popular alloys used in aerospace, automobile, marine, and mining industries due to excellent properties $[1,2]$.

The silicon based aluminium alloy A413, which was chosen for this work, is associated with the theoretical density of $2.66 \mathrm{~g} / \mathrm{cm}^{3}$. This alloy has been selected because of its good fluidity due to the presence of silicon content [1-5]. Also it is associated with excellent pressure tightness, good hot tear resistance, good castability, good machinability, high specific strength, and high corrosion resistance. Due to these properties, it finds use in numerous applications such as engine cylinder, piston, manifolds, and motor casings [6, 7]. The chemical composition of A413 aluminium alloy is represented in Table 1.

Metal casting is the most economical route to produce metallic components in which the liquid metal is directly poured into the mould cavity of the required size and shape. The major drawback of casting processes is the formation of casting defects such as porosity, segregation, and hot tears $[7,8]$. Further, the conventional casting processes cannot 
TABLE 1: Chemical composition of A413 aluminium alloy in wt. \%.

\begin{tabular}{lccccccccccc}
\hline & $\mathrm{Cu}$ & $\mathrm{Mg}$ & $\mathrm{Si}$ & $\mathrm{Fe}$ & $\mathrm{Mn}$ & $\mathrm{Ni}$ & $\mathrm{Zn}$ & $\mathrm{Pb}$ & $\mathrm{Sn}$ & $\mathrm{Ti}$ & $\mathrm{Al}$ \\
\hline Standard & $0.25 \max$ & $0.15 \max$ & $10.0-13.0$ & $0.60 \max$ & $0.50 \max$ & $0.10 \max$ & $0.30 \max$ & $0.10 \max$ & $0.10 \max$ & 0.20 max & Reminder \\
Tested & 0.1 & 0.1 & 11.81 & 0.56 & 0.5 & 0.1 & 0.1 & 0.1 & 0.05 & 0.1 & Reminder \\
\hline
\end{tabular}

achieve the defect-free castings and desirable properties that satisfy the current demand.

Squeeze casting is one of the modern casting techniques that respond best to the current demand. It is a hybrid metal casting/liquid-metal forging process, in which the molten metal solidifies under pressure within the closed die cavity, positioned between the plates of a hydraulic unit. The castings produced through squeeze casting route eliminate the defects with superior properties over the conventional castings due to fast heat transfer rate [9-11].

To achieve a sound casting in squeeze casting route, the most dominant process parameter is level of applied pressure, although die preheating temperature, pouring temperature, and superheat are also important [9]. The die temperature is usually held between 200 and $300^{\circ} \mathrm{C}$ for aluminium alloy while the applied pressure varies between 70 and $210 \mathrm{MPa}$ [12]. The process parameters in squeeze casting technique were studied and reported that the squeeze pressure and pouring temperature of $125 \mathrm{MPa}$ and $700^{\circ} \mathrm{C}$, respectively, gave good combination of hardness and tensile properties in Al$8 \% \mathrm{Si}$ alloys having an aspect ratio not greater than 2.5:1 [13]. Squeeze pressure variation plays a major role in the formation of finer microstructure leading to good mechanical properties. Further, higher pressure decreases the percentage of porosity and increases the density of the cast alloy [14, 15]. Squeeze casting accounted for $15-40 \%$ improvement of mechanical properties than gravity die casting process [16]. The effect of applied pressure (1-75 MPa) on A413 Al-Si alloy was studied and reported that increasing the applied pressure results in increase of about 3.4\% in density, 63\% in UTS, $2.6 \%$ in percentage elongation, and $50 \%$ in hardness [17].

In recent years, Artificial Neural Networks (ANNs) approach is one of the most powerful computing modeling facilities, based on statistical approach. This is currently being used in many fields of engineering for modeling complex relationships which are arduous to describe with physical models. Neural networks, as used in artificial intelligence, have traditionally been viewed as simplified models of neural processing in the human brain. The origins of neural networks are based on efforts to model information processing in biological systems, which may rely largely on parallel processing as well as implicit instructions based on recognition of patterns of "sensory" input from external sources. Artificial Neural Network (ANN) is a potent technique in the prediction of the properties and quite useful instead of time-consuming experimental processes and avoids costly manufacturing in analyzing the effects. To avoid cost incurred in manufacturing, ANN simulation model using LevenbergMarquardt (LM) algorithm was developed and the performance in predictions was contemplated with experimentally measured values [18-21].

Determination of the optimum squeeze cast process parameters of A413 aluminum alloy castings depending upon several factors and having subjected to many performance constraints is often complex and prolonged. This complexity could be made simple with the utilization of quantitative and statistical analysis, as the mechanical properties of the castings are dependent upon the relative process parameters. Several authors have optimized the squeeze casting process parameters for various Aluminum alloy grades using Taguchi method, Grey relational analysis, and genetic algorithm. It was reported that squeeze pressure, die preheating temperature, and melt temperature were found to be the major contributing factors on the mechanical properties of the castings and evaluated the optimal solutions for each factor [22-29]. Among all the available methods of Design of Experiments (DOE), Full Factorial Design (FFD) is a strong candidate in evaluating significant process parameters that can be employed to develop the casting process by evaluation of combined independent factors [30]. Analysis of Variance (ANOVA) is one of the proficient tools that allow the simultaneous study of the effects of all the input parameters and determines the significant parameters by carrying out a single analysis [30, 31].

Antecedent research works annotated that the hardness, ultimate tensile strength, and yield strength of A413 Al alloy, processed by various casting processes, had exhibited considerable improvement in mechanical properties. Among several casting techniques, squeeze casting route shows better properties due to the application of various influenced process parameters. The process parameters vary with volume and shape (symmetrical/nonsymmetrical and aspect ratio) of the castings [13, 23-29] and also with different grades of aluminium alloy which are tabulated in Table 2. However, optimization of mechanical properties of A413 aluminium alloy (cylindrical castings of dia $50 \mathrm{~mm}$ and height $200 \mathrm{~mm}$ size) produced through squeeze casting route using FFD for varying squeeze pressure, die preheating temperature, and molten metal temperature modeled with artificial neural network had not been reported in the scientific community. The controlled and uncontrolled parameters during the process of experimentation may affect the truthfulness of the results. These discrepancies are sorted out by the usage of ANN, by means of modelling and predicting the responses. Also it is an attractive processing method since it is relatively inexpensive and offers a wide selection of input and output data conditions. This helps us in meeting with the botherations of time and cost. This work also focuses on the application of statistical technique to determine the precise influence of process parameters on the mechanical properties of the castings. The inquisition is enumerated and presented.

\section{Experimental Technique}

2.1. Materials and Methods. The metallic H13 die steel die was firmly seated over the $250 \mathrm{MPa}$ (50 Ton) capacity hydraulic 
TABLE 2: Comparison of antecedent research works.

\begin{tabular}{|c|c|c|c|c|c|}
\hline Process & Metal/reinforcement & Input process parameters & UTS & Hardness & Reference \\
\hline Pressure die casting & $\begin{array}{c}\text { LM6 + } 15 \text { wt. \%, size } \\
44 \mu \mathrm{m} \mathrm{Al}_{2} \mathrm{O}_{3}\end{array}$ & $\begin{array}{l}100 \text { Mpa pressure } 250 \text { die } \\
\text { temperature and } 700 \text { melt } \\
\text { temperature }\end{array}$ & $145 \mathrm{MPa}$ & $129 \mathrm{HBN}$ & [9] \\
\hline Squeeze casting & $\mathrm{Al}-8 \% \mathrm{Si}$ & $\begin{array}{c}125 \mathrm{Mpa} \text { pressure } 250 \text { die } \\
\text { temperature and } 700 \text { pouring } \\
\text { temperature }\end{array}$ & $232 \mathrm{Mpa}$ & $58.0 \mathrm{HRF}$ & {$[13]$} \\
\hline Squeeze casting & $2024 \mathrm{Al}$ alloy & $\begin{array}{l}70 \text { Mpa pressure } 250 \text { die } \\
\text { temperature, and750 pouring } \\
\text { temperature }\end{array}$ & $<250 \mathrm{Mpa}$ & - & {$[14]$} \\
\hline Squeeze casting & $7075+\mathrm{SiC}$ & $\begin{array}{c}10 \% \mathrm{Wt} \mathrm{SiC,} 70 \mathrm{TON} \text { pressure, } \\
300 \text { die temperature, and } 780 \\
\text { pouring temperature }\end{array}$ & $210 \mathrm{Mpa}$ & $138 \mathrm{VHN}$ & {$[15]$} \\
\hline Squeeze casting & $\begin{array}{c}\text { AC2A-Ni coated } \mathrm{SiC} \\
\text { alloy }\end{array}$ & $\begin{array}{c}10 \% \mathrm{Wt} \mathrm{SiC}, 100 \mathrm{Mpa} \text { pressure, } \\
250 \text { die temperature, } 725 \text { melt } \\
\text { temperature, and } 45 \mathrm{sec} \text { pressure } \\
\text { duration }\end{array}$ & $402-419 \mathrm{Mpa}$ & $141-147 \mathrm{BHN}$ & {$[23]$} \\
\hline Squeeze casting & LM 24 & $\begin{array}{c}106 \mathrm{Mpa} \text { pressure, } 150 \text { die } \\
\text { temperature, } 45 \mathrm{sec} \text { pressure } \\
\text { duration, } 750 \text { melt temperature. }\end{array}$ & $258 \mathrm{Mpa}$ & $93 \mathrm{BHN}$ & {$[24]$} \\
\hline Squeeze casting & AC2A alloy & $\begin{array}{l}100 \text { Mpa pressure, } 200 \text { die } \\
\text { temperature, } 725 \text { melt } \\
\text { temperature, hot die steel die, } \\
\text { and } 45 \mathrm{sec} \text { pressure duration }\end{array}$ & $328 \mathrm{Mpa}$ & $115 \mathrm{BHN}$ & {$[27]$} \\
\hline Squeeze casting & LM24 & $\begin{array}{l}\text { 105.901 Mpa pressure, } 35.103 \text { die } \\
\text { temperature, pressure duration } \\
15.124 \mathrm{sec} \text {, and } 750 \text { pouring } \\
\text { temperature }\end{array}$ & $272.258 \mathrm{Mpa}$ & $98.013 \mathrm{BHN}$ & {$[29]$} \\
\hline
\end{tabular}

unit base plates. The punch was firmly fitted in a hydraulic unit to apply the required squeeze pressure. The preheater with maximum range of $500^{\circ} \mathrm{C}$ capacity has thermocouple arrangements to control the temperature of the die accurately. A bottom pouring red hot electric furnace (maximum range of $1200^{\circ} \mathrm{C}$ ) with 2 -liter capacity has been used to melt the metal. A preheated pathway unit with $400^{\circ} \mathrm{C}$ capacity is inbuilt in this setup. Standard hexachloroethylene $\left(\mathrm{C}_{2} \mathrm{Cl}_{6}\right)$ degasser was used to remove the entrapped gases and other impurities/slag in the molten metal. The entire squeeze casting setup is shown in Figure 1.

The experimentation was carried out by varying the influencing input parameters such as squeeze pressure, die preheating temperature, and melt temperature. The molten metal from the bottom pouring furnace was transferred into the preheated die through preheated pathway within few seconds, so as to avoid melt temperature loss and turbulence of molten metal flow.

The squeeze pressure was applied on the molten metal by lowering the punch which is attached to the hydraulic unit with varying squeeze pressure $(70,105$, and $140 \mathrm{MPa})$, die preheating temperatures $\left(150^{\circ} \mathrm{C}, 225^{\circ} \mathrm{C}\right.$, and $\left.300^{\circ} \mathrm{C}\right)$, and melt temperatures $\left(650^{\circ} \mathrm{C}, 725^{\circ} \mathrm{C}\right.$, and $\left.800^{\circ} \mathrm{C}\right)$ [12]. The compression loads were applied at a delay time of about five seconds after pouring molten metal and retained on the solidifying molten metal for a period of 60 seconds to produce sound castings (diameter $50 \mathrm{~mm} \times$ height $200 \mathrm{~mm}$ ). The

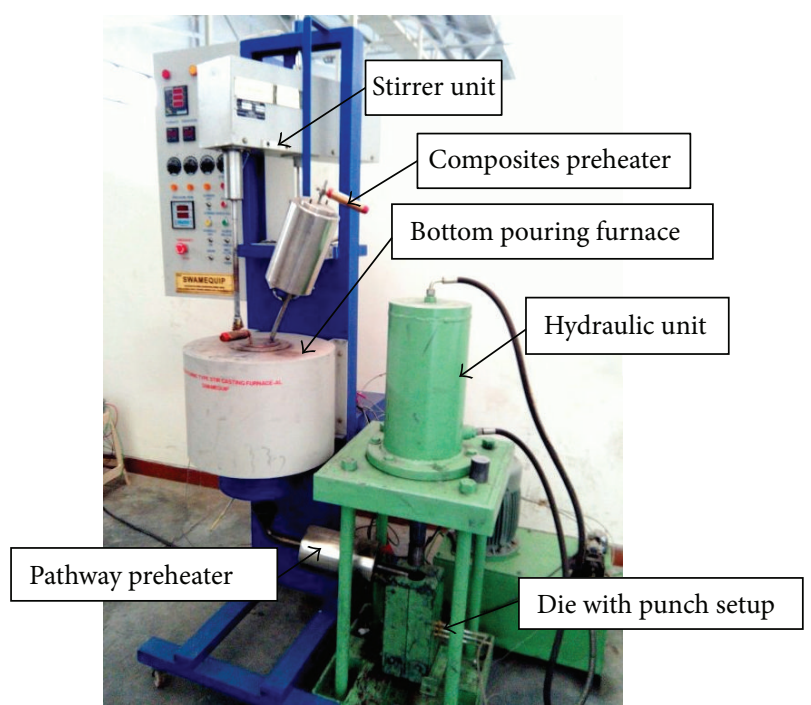

FIGURE 1: Squeeze casting setup.

castings were performed as per design of experiments (DOE) approach using L27 orthogonal array.

2.2. Full Factorial Design. The structure of the selected design of experiments should be such that the experimental investigation is completely factorial. This means that every possible 
TABLE 3: Factors and their levels adopted for the $3^{3}$ (L27) full factorial design used.

\begin{tabular}{lccc}
\hline Factors & Level 1 & Level 2 & Level 3 \\
\hline Squeeze pressure $(\mathrm{MPa})$ & 70 & 105 & 140 \\
Die preheating temperature $\left({ }^{\circ} \mathrm{C}\right)$ & 150 & 225 & 300 \\
Molten metal temperature $\left({ }^{\circ} \mathrm{C}\right)$ & 650 & 725 & 800 \\
\hline
\end{tabular}

combination between the levels of the various factors is analyzed. For the $3^{3}$ full factorial design, squeeze pressure, die preheating temperature, and melt temperature were selected as factors and each was run at three levels as represented in Table 3. The 27 different combinations determined by Minitab 16 statistical software were evaluated. The preliminary investigation of the factors was performed to evaluate the effects of each parameter on the response by using $P$ value and $F$ test. The $P$ value for each factor tests the null hypothesis that the coefficient is equal to zero (no effect). A low $P$ value $(<0.05)$ indicates that you can reject the null hypothesis; that is, the factor has a meaningful addition towards the response variable. Conversely, a larger (insignificant) $P$ value suggests that the factor is not associated with changes in the response. The Analysis of Variance (ANOVA) was adopted for testing the significance of main effects on response [32-35].

2.3. Hardness Test and Tensile Test. Cast samples were machined to the testing conditions and for each type of test, three specimens were prepared. For Brinell hardness (BHN) test, $250 \mathrm{~kg}$ load for 10 to 15 seconds was applied through a ball indenter of $10 \mathrm{~mm}$ on the polished specimen surface and hardness values were measured in three spots of the cast specimen areas. Universal testing machine was employed for performing tensile test on the specimens. Three tensile test specimens were prepared as per the ASTM standard [36]. From the tensile test conducted, the UTS and yield strength readings for all the specimens were noted for each set. The average value is taken for further processing, it was shown in Table 4.

2.4. Microscopy. For microscopic examination, specimens of cast samples of $15 \mathrm{~mm}$ diameter and $10 \mathrm{~mm}$ thickness were first grinded through emery papers $(320,400,600,800,1200$, and 1500 grit emery papers) followed by polishing by 6micrometer diamond paste. The samples were then etched with Keller's reagent to obtain better contrast $\left(2.5 \mathrm{~mL} \mathrm{HNO}_{3}\right.$, $1.5 \mathrm{~mL} \mathrm{HCl}, 1.0 \mathrm{~mL} \mathrm{HF}$, and $95.0 \mathrm{~mL}$ Water) and dried by an electric drier. Well-formed grain boundaries were observed by a metallurgical microscope having 100x magnification. All the specimens were prepared and responses were tested as per ASTM Standard [36]. Cast samples and tested specimens are shown in Figures 2, 3(a), and 3(b).

2.5. Modeling of Process Variables. To ensure the definiteness of the experimental results an ANN model was developed with which all the responses were predicted. ANN with Back Propagation (BP) algorithm has been adopted in this model. There are several algorithms available among which the Levenberg-Marquardt algorithm (TRAINLM) will have the



FIGURE 2: Cast samples made from squeeze casting process.

fastest convergence. This BP neural network is a multilayer of the network architecture including the input layer, the hidden layer(s), and the output layer. In the BP neural network, initially the weights of the outputs are calculated randomly. However, the outputs so calculated are compared with the actual/desired outputs by the network and the error is transmitted to the initial layer, which results in correction of the weights. The training iteration process may be terminated either by attaining a convergence limit or simply by limiting the total number of iterations [37-39]. Squeeze casting parameters such as squeeze pressure, die preheating temperature, and melt temperature were given as input parameters to ANN model. Mechanical properties such as hardness, ultimate tensile strength, and yield strength were given as output parameters. The input/output dataset of the model is illustrated schematically in Figure 4.

The networks consist of three layers: the input layer, the hidden layer, and the output layer. Now, the designed network has three input neurons and three output neurons. Then the problem of determining the optimal number of hidden neurons is a crucial one. The number of hidden neurons must be sufficiently large to realize a certain function. Several structures have to be considered with different numbers of hidden neurons to determine the best configuration [37-40].

2.5.1. Designing, Training, and Testing of Neural Network. In ANN model, the three input parameters, namely, squeeze pressure, die preheating temperature, and melt temperature which has a major influence on mechanical properties of casting, and the output parameters were constrained to hardness, ultimate tensile strength, and yield strength. The data for training and testing have been taken from experiments conducted as per DOE. From the data of 27 experiments, 18 experiments (two-third) were selected for training and 9 experiments (one-third) were selected for testing. Both input dataset and output dataset were fed into neural network toolbox. Before training and testing the network, the input and output dataset were normalized to avoid suppressing. Three neurons corresponding to three inputs were fixed in input layer, three neurons corresponding to three outputs were fixed in output layer, and one/two neurons were fixed in hidden layer. After designing the network, selected training data of both input data and output data (18 dataset) was fed into the 3-1-3 ANN architecture initially. Then, the test input data (9-input data only) was fed into the same trained architecture and the performance was checked in terms of correlation coefficient and percentage of prediction error. 
TABLE 4: Assigned orthogonal L27 with the acquired data.

\begin{tabular}{|c|c|c|c|c|c|c|}
\hline S. number & $\begin{array}{c}\text { Squeeze pressure } \\
(\mathrm{MPa})\end{array}$ & $\begin{array}{l}\text { Die preheating } \\
\text { temperature }\left({ }^{\circ} \mathrm{C}\right)\end{array}$ & $\begin{array}{c}\text { Melt temperature } \\
\left({ }^{\circ} \mathrm{C}\right)\end{array}$ & Hardness (BHN) & UTS (MPa) & $\mathrm{YS}(\mathrm{MPa})$ \\
\hline 1 & 70 & 150 & 650 & 72 & 252 & 149 \\
\hline 2 & 70 & 225 & 650 & 76 & 266 & 147 \\
\hline 3 & 70 & 300 & 650 & 65 & 236 & 136 \\
\hline 4 & 70 & 150 & 725 & 71 & 249 & 146 \\
\hline 5 & 70 & 225 & 725 & 78 & 269 & 152 \\
\hline 6 & 70 & 300 & 725 & 66 & 237 & 135 \\
\hline 7 & 70 & 150 & 800 & 72 & 239 & 135 \\
\hline 8 & 70 & 225 & 800 & 75 & 248 & 141 \\
\hline 9 & 70 & 300 & 800 & 62 & 232 & 131 \\
\hline 10 & 105 & 150 & 650 & 84 & 285 & 158 \\
\hline 11 & 105 & 225 & 650 & 87 & 289 & 167 \\
\hline 12 & 105 & 300 & 650 & 79 & 258 & 142 \\
\hline 13 & 105 & 150 & 725 & 89 & 284 & 166 \\
\hline 14 & 105 & 225 & 725 & 88 & 293 & 167 \\
\hline 15 & 105 & 300 & 725 & 81 & 274 & 158 \\
\hline 16 & 105 & 150 & 800 & 78 & 265 & 156 \\
\hline 17 & 105 & 225 & 800 & 87 & 291 & 161 \\
\hline 18 & 105 & 300 & 800 & 79 & 258 & 149 \\
\hline 19 & 140 & 150 & 650 & 94 & 298 & 171 \\
\hline 20 & 140 & 225 & 650 & 92 & 299 & 174 \\
\hline 21 & 140 & 300 & 650 & 87 & 286 & 162 \\
\hline 22 & 140 & 150 & 725 & 94 & 301 & 167 \\
\hline 23 & 140 & 225 & 725 & 95 & 305 & 176 \\
\hline 24 & 140 & 300 & 725 & 87 & 287 & 169 \\
\hline 25 & 140 & 150 & 800 & 91 & 285 & 166 \\
\hline 26 & 140 & 225 & 800 & 92 & 299 & 171 \\
\hline 27 & 140 & 300 & 800 & 83 & 284 & 162 \\
\hline
\end{tabular}

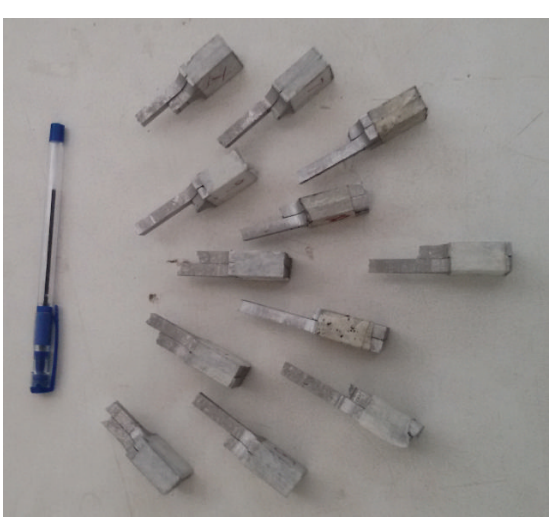

(a)

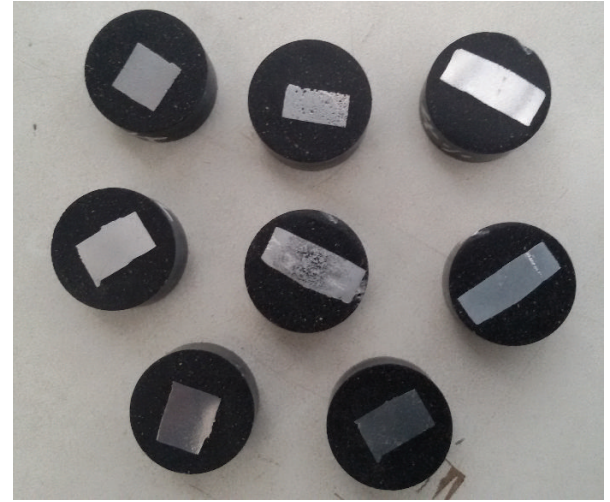

(b)

FIgURE 3: Tested specimens (a) UTS and YS (b) hardness and microstructure. 




Figure 4: ANN model.

Similarly the performance of other various architectures was checked in the same manner as shown in Table 5 [37-41].

Then the data were trained and tested as shown in the flow diagram of Figure 5 and the percentage of error is calculated using the following formulae:

$$
\begin{aligned}
& \text { Percentage of error } \% \\
& =\left(\frac{\text { Actual Value }- \text { Predicted Value }}{\text { Actual Value }}\right) * 100 .
\end{aligned}
$$

Table 6 shows the experimental and predicted results with the predicted error percentage. Similarly predictions were done and graphs were plotted as shown in Figures 6-8.

\section{Results and Discussions}

The main objective of the present work is to study, predict, and analyze the mechanical properties (hardness, ultimate tensile strength, and yield strength) of squeeze casting process parameters of A413 aluminium alloy castings using BP neural network and statistical analysis.

\subsection{Performance Measurement of Neural Network for Experi-} mental Data. In order to determine the optimal architecture, 40 different networks with different numbers of layers and neurons in the hidden layer have been designed and tested for castings. The performance capabilities of each network are examined based on the correlation coefficient between the network predictions and the experimental values using the test and the entire dataset. It is concluded that the selection of optimum architecture depends on maximum error $\%$, minimum error $\%$, mean error $\%$, and the correlation coefficient. From Tables 5 and 6 , it is identified that the networks with two hidden layers and four neurons in each layer (3-44-3) produced the best performance for each of the output parameters. It was observed that the correlation coefficient was above 0.95 for architecture (3-4-4-3) which has high level of accuracy for prediction. It is also observed that the mean correlation coefficient for the architecture (3-4-4-3) is 0.96615 which is better than the previous architectures. Hence, further, the average percentage error $(0.92376)$ was also less than $\pm 3 \%$ which means the ANN predicted results were very much closer to the experimental (actual) results shown in Figures 6-8. It reveals that the prediction of ANN model was found to be in good agreement with experimental data.

Therefore, the selected 3-4-4-3 ANN architecture model can be used for predicting the mechanical properties of A413 Al alloy castings processed within the input parameters of squeeze pressure, die preheating temperature, and melt temperature. The process variables that lead to the cast component with the desired properties can be interpolated with the help of the optimal model. This is well suited for aluminum metal casting industries where the real-time experimental runs can be reduced to a greater extent which leads to time and cost saving [38].

3.2. Influence of Process Variables on Mechanical Properties. The influential parameters were squeeze pressure, die preheating temperature, melt temperature, pressure holding time, and die material. Among them the first three parameters were taken as variables and other two parameters were taken as fixed ones. The effect of each variable parameter is discussed as follows. The results obtained showed scientific influence of each parameter on the response.

3.2.1. Effect of Squeeze Pressure on Mechanical Properties. The scientific theory for obtaining better results at the maximum squeeze pressure is as follows. During the solidification of casting process, an air gap is formed between the metal and mould interface which is found to have a major influence on the mechanical properties of casting [11]. The air gap reduces the value of heat transfer coefficient in the interface, resulting in prolonged solidification time that leads to formation of microporosity in the castings. In squeeze casting process, the applied squeeze pressure reduces the air gap and decreases the solidification time [27-29].

It also reveals that the maximum squeeze pressure increases the metal mold contact which accelerates the solidification process leading to formation of fine dendritic structure of the castings as compared to lower pressure levels. Fine dendritic structure results in high hardness, UTS, and yield strength [11-14, 27-29].

Figures 9-14 show the effect of squeeze pressure under different levels such as 70,105 , and $140 \mathrm{MPa}$. By varying the die preheating temperature as $150^{\circ} \mathrm{C}, 225^{\circ} \mathrm{C}$, and $300^{\circ} \mathrm{C}$ and melt temperature $650^{\circ} \mathrm{C}, 725^{\circ} \mathrm{C}$, and $800^{\circ} \mathrm{C}$, it is observed that the maximum results were obtained for the maximum squeeze pressure of $140 \mathrm{MPa}$. Coarse and fine dendritic structure is formed when the sample solidified under $70 \mathrm{MPa}$ and $105 \mathrm{MPa}$. When the applied squeeze pressure increased to $140 \mathrm{MPa}$, ideal fine dendritic structure is obtained for this volume and shape of the castings. Further increase of applied pressure has no significant effect on the dendritic structure [11-13].

3.2.2. Effect of Die Preheating Temperature. The scientific theory for obtaining better results at a preheating temperature is 




FIgURE 5: Flow Diagram for training and testing of ANN model.

as follows. Initially before the pouring of molten metal, the die preheating helps to evaporate the entrapped air/gases in the die cavity. After pouring, the preheating of the die affects the rate of heat transfer as it increases the solidification time. The die preheating temperature range depends upon the material, volume, and the shape of the casting which may result in defect-free sound casting in a quality acceptable range.

To investigate the effect of varying die preheating temperature, squeeze pressure and melt temperature were fixed since the die preheating temperature is an important parameter which affects the heat transfer rates and consequently the cooling properties of the castings in this process. With higher the die preheating temperature results in delay of solidification time which in turn leads to formation of coarse dendritic structure and reduces the die life, causing hot spots and shrinkage pores. Whereas lower the die pre heating temperature leads to thermal failures in the dies, cold laps on the surface of the castings and air entrapped in the casting resulting in defective casting [10-13].

Figures 9-14 show the effect of different die preheating temperature $\left(150^{\circ} \mathrm{C}, 225^{\circ} \mathrm{C}\right.$, and $\left.300^{\circ} \mathrm{C}\right)$, squeeze pressure $(70,105$, and $140 \mathrm{MPa})$, and the melt temperature $\left(650^{\circ} \mathrm{C}\right.$, $725^{\circ} \mathrm{C}$, and $800^{\circ} \mathrm{C}$ ). By maintaining different levels of squeeze pressure and melt temperature, it is observed that the better results were obtained for a die preheating temperature of $225^{\circ} \mathrm{C}$ for this volume and shape of the castings.

3.2.3. Effect of Melt Temperature. The scientific theory for obtaining better results at a melt temperature is as follows. Higher the melt temperature leads to formation of coarse 


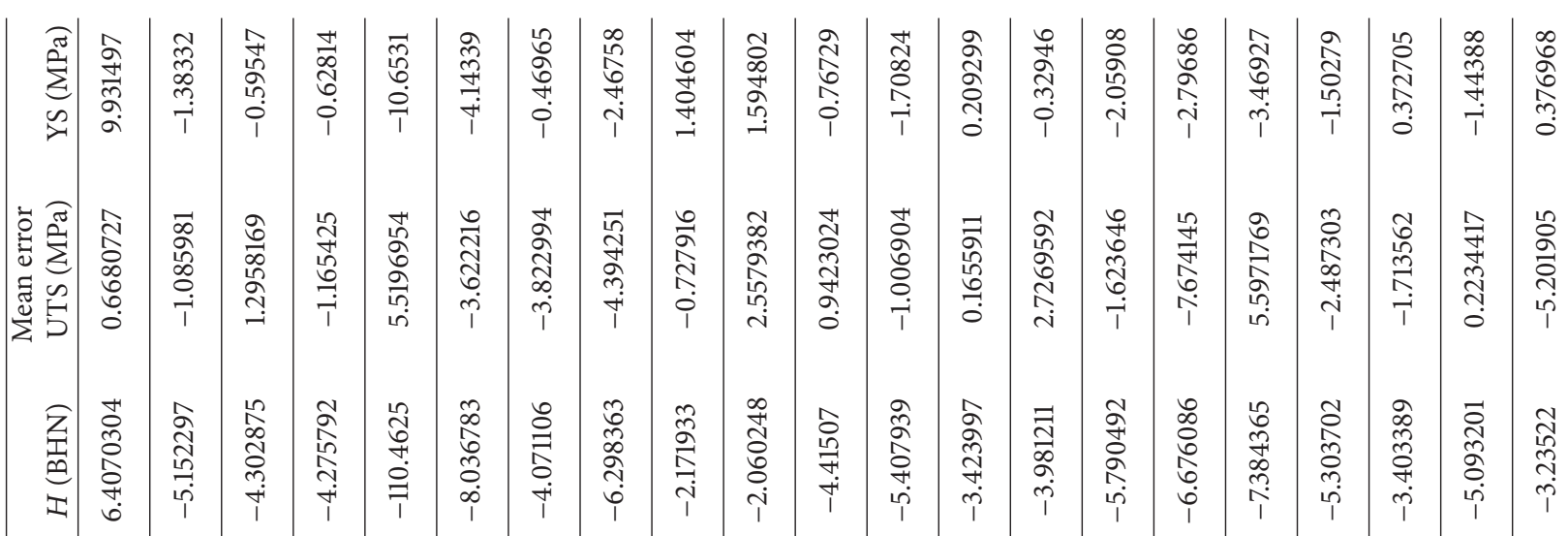

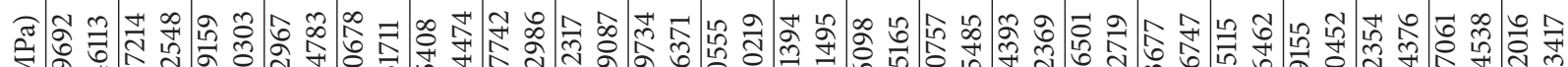

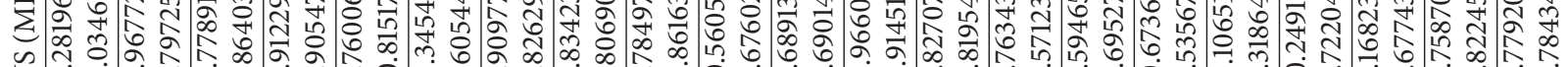



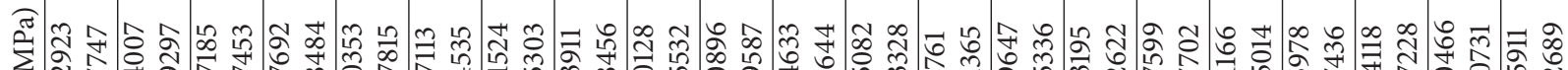

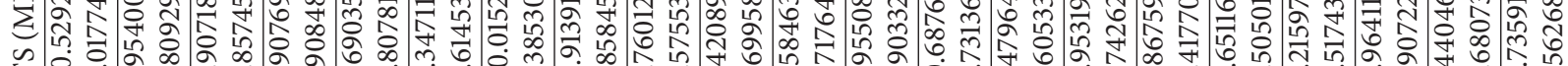

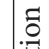



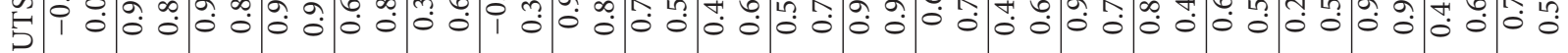

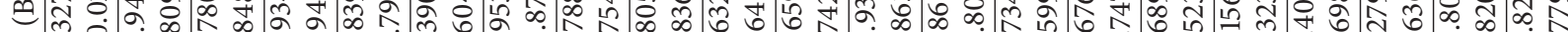

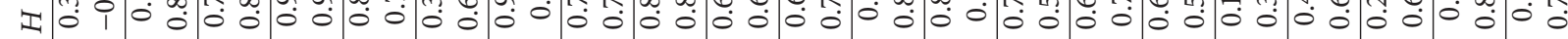




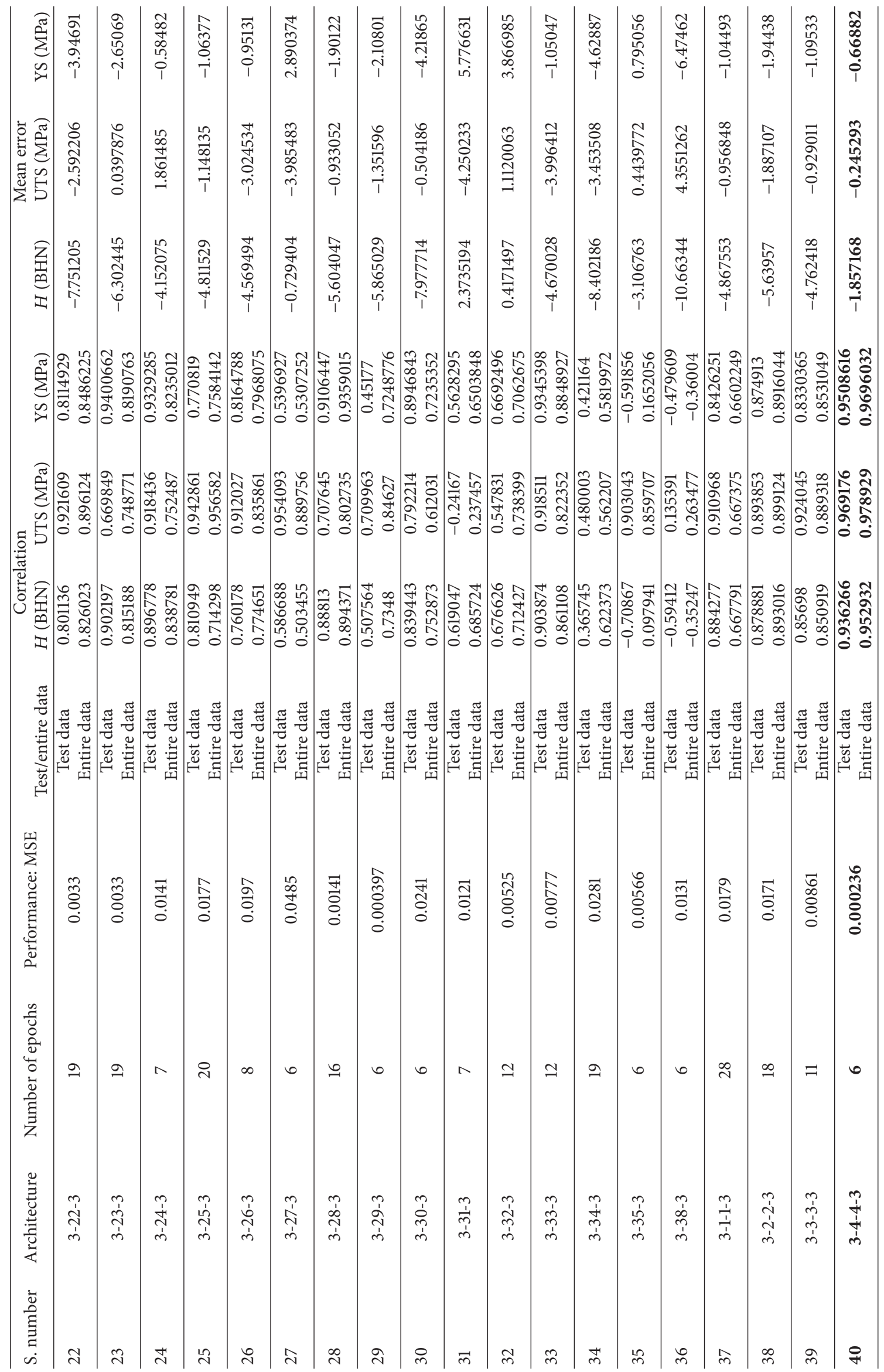


TABLE 6: Experimental and ANN results of training and testing data.

\begin{tabular}{|c|c|c|c|c|c|c|c|c|c|}
\hline \multirow{2}{*}{ S. number } & \multicolumn{3}{|c|}{ Experimental results } & \multicolumn{3}{|c|}{ ANN results } & \multicolumn{3}{|c|}{ Predicted error } \\
\hline & $H$ & UTS & YS & $H$ & UTS & YS & $H$ & UTS & YS \\
\hline \multicolumn{10}{|c|}{ Training set } \\
\hline 1 & 72 & 252 & 149 & 74.17924 & 255.3464 & 150.7671 & -3.02672 & -1.32792 & -1.18595 \\
\hline 2 & 76 & 266 & 147 & 78.15725 & 255.9242 & 142.0319 & -2.83849 & 3.787894 & 3.379629 \\
\hline 3 & 65 & 236 & 136 & 70.89582 & 238.4725 & 135.2735 & -9.07049 & -1.04765 & 0.534189 \\
\hline 4 & 71 & 249 & 146 & 71.6759 & 247.9369 & 147.3548 & -0.95197 & 0.426944 & -0.92793 \\
\hline 5 & 78 & 269 & 152 & 81.66384 & 271.4753 & 153.9232 & -4.69723 & -0.92017 & -1.26526 \\
\hline 6 & 72 & 239 & 135 & 71.65555 & 240.363 & 139.2488 & 0.478404 & -0.57029 & -3.14725 \\
\hline 7 & 75 & 248 & 141 & 75.12859 & 247.1022 & 141.6824 & -0.17145 & 0.362011 & -0.48396 \\
\hline 8 & 87 & 289 & 167 & 85.63843 & 285.8119 & 164.3899 & 1.565027 & 1.103139 & 1.562942 \\
\hline 9 & 79 & 258 & 142 & 78.52493 & 257.8554 & 143.3112 & 0.601349 & 0.056062 & -0.92335 \\
\hline 10 & 88 & 293 & 167 & 88.26898 & 291.553 & 167.574 & -0.30566 & 0.493862 & -0.34373 \\
\hline 11 & 81 & 274 & 158 & 82.02498 & 274.0065 & 155.8774 & -1.26541 & -0.00239 & 1.343432 \\
\hline 12 & 87 & 291 & 161 & 89.01555 & 286.0511 & 163.069 & -2.31672 & 1.70066 & -1.28508 \\
\hline 13 & 79 & 258 & 149 & 78.54525 & 258.7912 & 148.6646 & 0.575627 & -0.30668 & 0.225122 \\
\hline 14 & 92 & 299 & 174 & 92.93316 & 300.7147 & 172.4506 & -1.0143 & -0.57348 & 0.89045 \\
\hline 15 & 95 & 305 & 176 & 94.58353 & 304.0236 & 174.8126 & 0.438389 & 0.320127 & 0.674637 \\
\hline 16 & 91 & 285 & 166 & 90.14581 & 286.8076 & 166.1176 & 0.938668 & -0.63424 & -0.07087 \\
\hline 17 & 92 & 299 & 171 & 94.87449 & 304.6269 & 175.3976 & -3.12444 & -1.8819 & -2.57167 \\
\hline 18 & 83 & 284 & 162 & 84.7705 & 283.1482 & 163.473 & -2.13314 & 0.299932 & -0.90924 \\
\hline \multicolumn{10}{|c|}{ Testing set } \\
\hline 19 & 66 & 237 & 135 & 72.33027 & 240.346 & 135.6869 & -9.59132 & -1.41181 & -0.50878 \\
\hline 20 & 62 & 232 & 131 & 60.56261 & 237.9408 & 135.5271 & 2.318365 & -2.56069 & -3.45579 \\
\hline 21 & 84 & 285 & 158 & 92.38562 & 296.7993 & 170.5431 & -9.98288 & -4.14011 & -7.93869 \\
\hline 22 & 89 & 284 & 166 & 89.62359 & 286.8772 & 166.2851 & -0.70067 & -1.01309 & -0.17177 \\
\hline 23 & 78 & 265 & 156 & 77.80651 & 272.6354 & 158.4703 & 0.248062 & -2.88128 & -1.58353 \\
\hline 24 & 94 & 298 & 171 & 93.83024 & 300.7667 & 172.6961 & 0.180592 & -0.92844 & -0.99188 \\
\hline 25 & 87 & 286 & 162 & 83.94891 & 282.625 & 163.0893 & 3.507002 & 1.180066 & -0.67239 \\
\hline 26 & 94 & 301 & 167 & 91.36167 & 291.7642 & 168.4075 & 2.806739 & 3.068358 & -0.84281 \\
\hline 27 & 87 & 287 & 169 & 84.6408 & 284.7666 & 164.5869 & 2.71172 & 0.778174 & 2.611294 \\
\hline
\end{tabular}

Correlation coefficient $(R)$ : for hardness $R=0.95$, for UTS $R=0.95$, and for YS $R=0.96$.

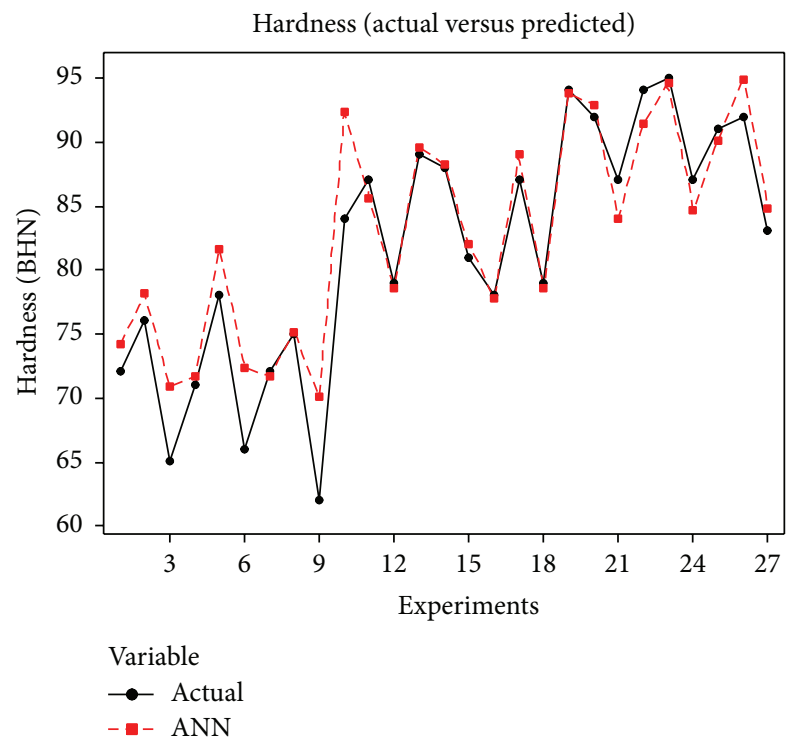

FIGURE 6: Actual versus ANN predicted results for hardness.

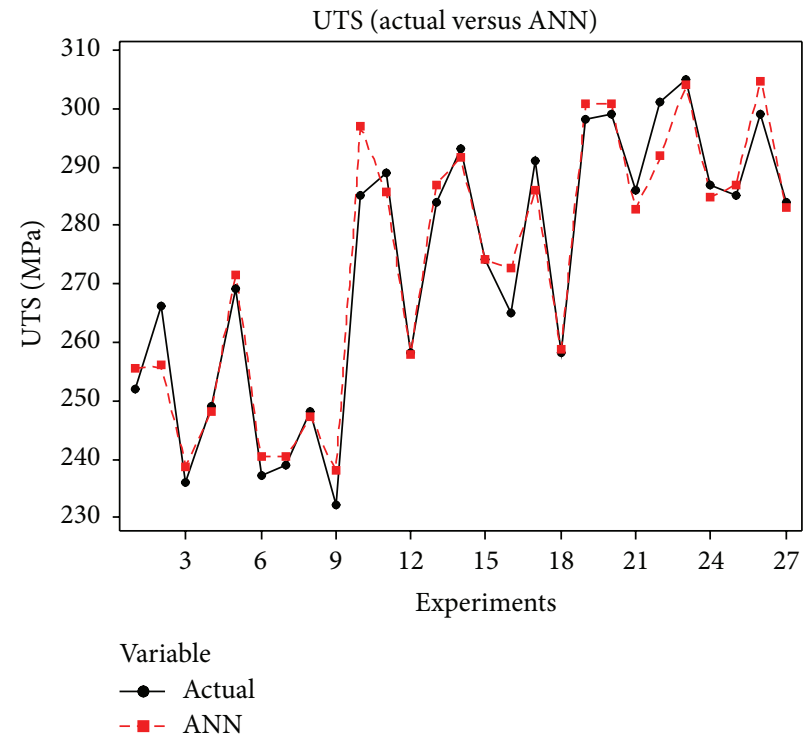

FIgURE 7: Actual versus ANN predicted results for UTS. 


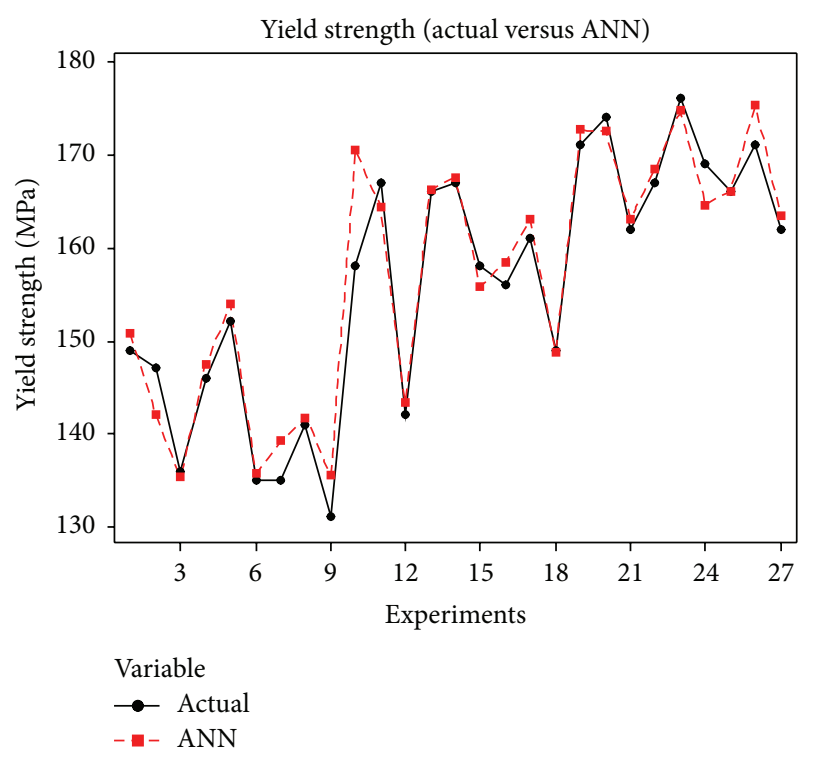

FIGURE 8: Actual versus ANN predicted results for YS.

dendritic structure due to delay in solidification time whereas lower the melt temperature leads to premature solidification in the castings. However, it must offer sufficient heat to avert premature solidification of the metals before the applied pressure. A suitable pouring temperature is dependent on several factors, such as the liquidus temperature, freezing range of the metal, and die complexity. Pouring temperature between 700 and $750^{\circ} \mathrm{C}$ plays an important role to change the grain structure evolution tendency with the applied pressure. When the pouring temperature is lower than the critical value, the applied pressure can obviously refine grains. On the contrary, when the pouring temperature is higher than the critical value, the applied pressure leads to the grain structure coarsening slightly [12].

Figures 9-14 show the effect of different melt temperatures $\left(650^{\circ} \mathrm{C}, 725^{\circ} \mathrm{C}\right.$, and $\left.800^{\circ} \mathrm{C}\right)$, die preheating temperatures $\left(150^{\circ} \mathrm{C}, 225^{\circ} \mathrm{C}\right.$, and $\left.300^{\circ} \mathrm{C}\right)$, and squeeze pressure $(70,105$, and $140 \mathrm{MPa})$. By maintaining different levels of die preheating temperature and squeeze pressure, it is observed that the better results were obtained for a melt temperature of $725^{\circ} \mathrm{C}$ for this volume and shape of castings [27-29].

3.3. Statistical Analysis. In order to determine the significance of each parameter that has involved in the process, an Analysis of Variance (ANOVA) was performed based on values of response (hardness, UTS, and yield strength), as shown in Tables 7-9. The determination coefficient $\left(R^{2}\right)$ value indicates the goodness of fits of the model [33-35]. In this case, the value of the mean determination coefficient $\left(R^{2}=\right.$ 93.096\%) and the value of the mean adjusted determination coefficient (adjusted $R^{2}=91.023 \%$ ) are high, which indicates a high significance of the model. It is evident that the squeeze pressure has a strong influence on mechanical properties contribution of about (70-78)\% followed by die preheating temperature $(15 \%-18 \%)$ and melt temperature. The results show that all three parameters including squeeze pressure, die
TABLE 7: Analysis of variance for hardness using adjusted SS for tests.

\begin{tabular}{lcccccc}
\hline Source & DF & Seq SS & Adj SS & Adj MS & $F$ & $P$ \\
\hline $\begin{array}{l}\text { Pressure } \\
\text { Die preheating }\end{array}$ & 2 & 1792.89 & 1792.89 & 896.44 & 182.12 & 0.000 \\
temperature & 2 & 354.67 & 354.67 & 177.33 & 36.03 & 0.000 \\
Melt temperature & 2 & 50.67 & 50.67 & 25.33 & 5.15 & 0.016 \\
Error & 20 & 98.44 & 98.44 & 4.92 & & \\
Total & 26 & 2296.67 & & & & \\
\hline
\end{tabular}

$S=2.21861, R$-Sq. $=95.71 \%$, and $R$-Sq. (adj.) $=94.43 \%$.

TABLE 8: Analysis of variance for UTS using adjusted SS for tests.

\begin{tabular}{lcccccc}
\hline Source & DF & Seq. SS & Adj. SS & Adj. MS & $F$ & $P$ \\
\hline Pressure & 2 & 8978.7 & 8978.7 & 4489.3 & 87.02 & 0.000 \\
$\begin{array}{l}\text { Die preheating } \\
\text { temperature }\end{array}$ & 2 & 2393.6 & 2393.6 & 1196.8 & 23.20 & 0.000 \\
Melt temperature & 2 & 362.0 & 362.0 & 181.0 & 3.51 & 0.049 \\
Error & 20 & 1031.8 & 1031.8 & 51.6 & & \\
Total & 26 & 12766.0 & & & & \\
\hline
\end{tabular}

$S=7.18254, R$-Sq. $=91.92 \%$, and $R$-Sq. (adj.) $=89.49 \%$.

TABLE 9: Analysis of variance for YS, using adjusted SS for tests.

\begin{tabular}{lcccccc}
\hline Source & DF & Seq SS & Adj SS & Adj MS & $F$ & $P$ \\
\hline Pressure & 2 & 2926.89 & 2926.89 & 1463.44 & 85.58 & 0.000 \\
$\begin{array}{l}\text { Die preheating } \\
\text { temperature }\end{array}$ & 2 & 693.56 & 693.56 & 346.78 & 20.28 & 0.000 \\
Melt temperature & 2 & 136.22 & 136.22 & 68.11 & 3.98 & 0.035 \\
Error & 20 & 342.00 & 342.00 & 17.10 & & \\
Total & 26 & 4098.67 & & & & \\
\hline
\end{tabular}

$S=4.13521$, and $R$-Sq. $=91.66 \%$, and $R$-Sq.(adj.) $=89.15 \%$.

preheating temperature, and melt temperature are effective in mechanical properties because their $P$ values are lower than 0.005. The main effects plot from Figures 9-11 reveals the effect of each process parameter on the mechanical properties of the castings. The mechanical properties increase drastically to the midlevel and then increase gradually due to applied squeeze pressure. This is because the dendritic structures are coarse and fine due to increase in applied pressure from $70 \mathrm{MPa}$ to $105 \mathrm{MPa}$ and further increase in pressure up to $140 \mathrm{MPa}$ causes a negligible increase in mechanical properties due to ideal fine dendritic structure.

In case of die preheating temperature and melt temperature it increases gradually to the midlevel and then decreases drastically to the higher level. This is because the lower die temperature $\left(150^{\circ} \mathrm{C}\right)$ and melt temperature $\left(650^{\circ} \mathrm{C}\right)$ cause casting defects and premature solidification resulting in lower mechanical properties whereas higher die preheating temperature $\left(300^{\circ} \mathrm{C}\right)$ and melt temperature $\left(800^{\circ} \mathrm{C}\right)$ cause solidification delay resulting in coarse dendritic structure which leads to loss in mechanical properties of the castings. The graphical model developed using the contour plot determines the effect of independent variables (squeeze pressure and die preheating temperature) on the dependent variables 
Data means

Pressure

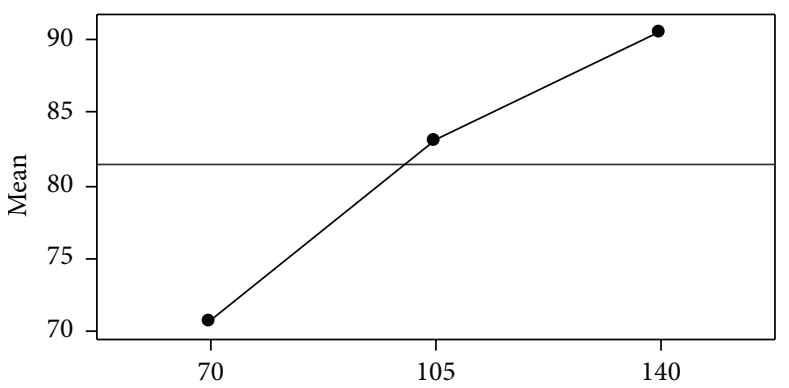

Die preheating temperature

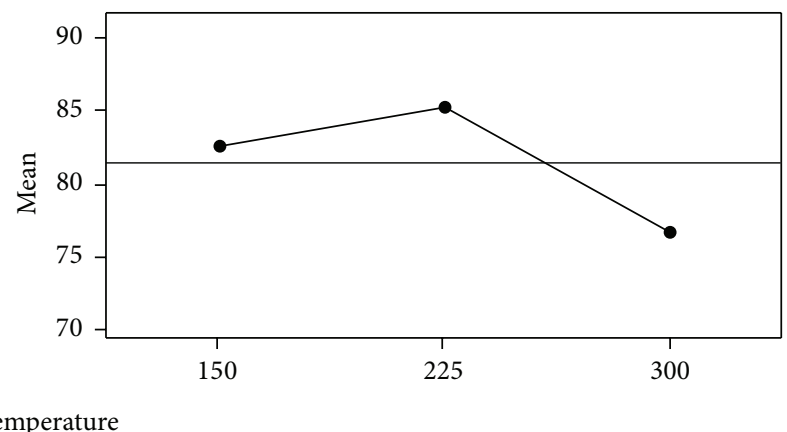



FIGURE 9: Main effect plots for hardness.



Data means
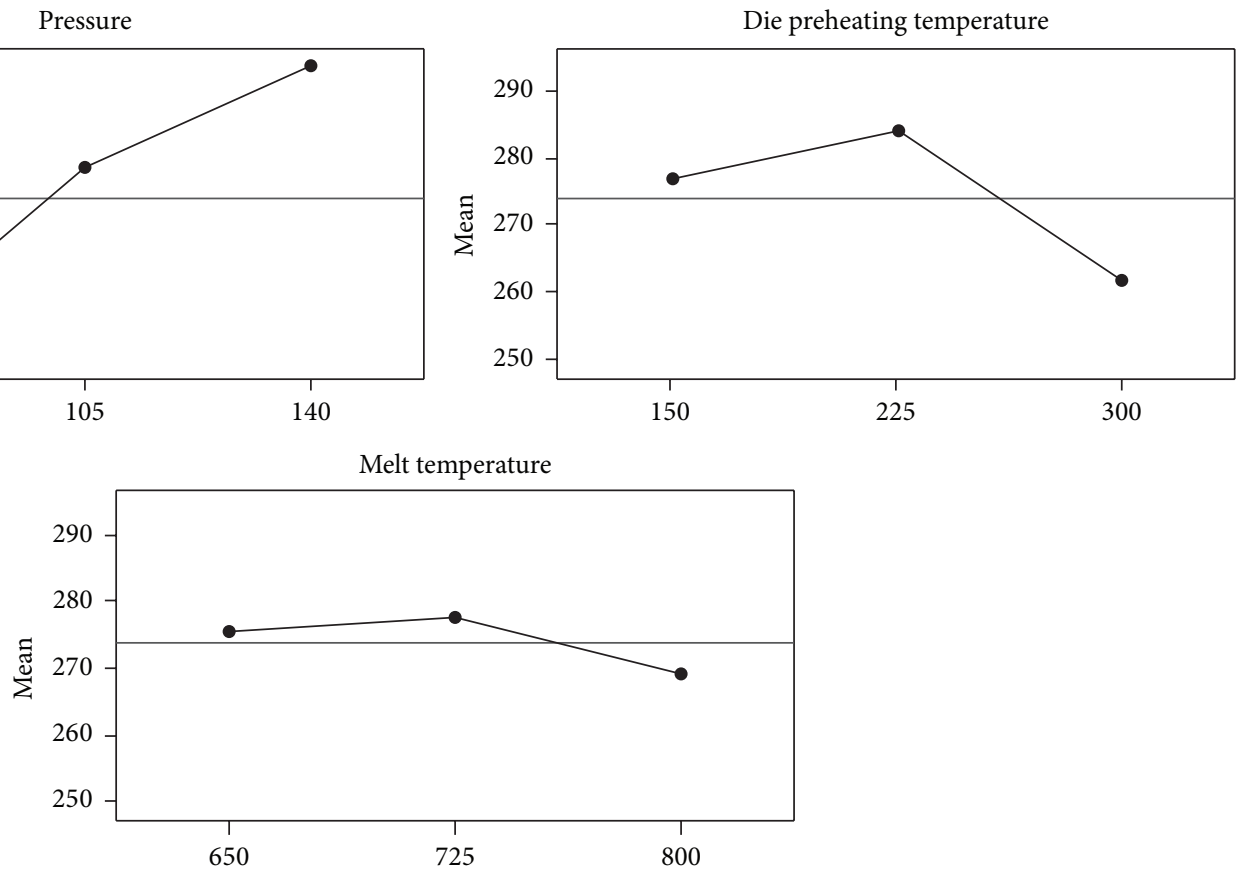

FIGURE 10: Main effect plots for UTS.

(hardness, UTS, and yield strength) as shown in Figures 1214. The dark green region in the contour plot indicates that higher mechanical properties are obtained due to the increase in squeeze pressure and optimal level of die preheating temperature. The blue region in the contour plot indicates the lower mechanical properties [27-29].
3.4. Effect of Process Parameters on Microstructure. Figures 15(a)-15(c) show the microstructures of the A413 alloy solidified under different squeeze pressures, which accelerate the formation of dendritic structure of the castings and it was studied through metallurgical microscope. Quantitative metallographic analysis shows that microporosity and other 




FIGURE 11: Main effect plots for YS.



Hardness
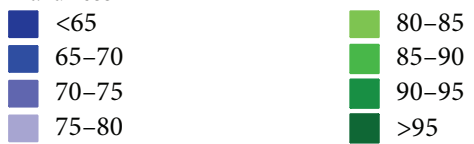

FIGURE 12: Contour plot for hardness versus die preheating temp and pressure.

defects are eliminated significantly with the increase in applied squeeze pressure. The microstructure of the cast samples consists of white regions of $(\alpha-\mathrm{Al})$ alpha aluminium dendritic structure in the black regions of $(\alpha-\mathrm{Al}+\mathrm{Si})$ eutectic matrix.

The dendritic branches act as the load carrying member in the matrix. By the refinement of dendritic branches there is a significant improvement in the mechanical properties of the castings. The cast sample of A413 aluminum alloy at squeeze


FIGURE 13: Contour plot for UTS versus die preheating temperature and pressure.

pressure $140 \mathrm{MPa}$ with die preheating temperature of $225^{\circ} \mathrm{C}$ and melt temperature of $725^{\circ} \mathrm{C}$ reveals an ideal fine dendritic structure and shows superior mechanical properties than others. The coarse and fine dendritic structure was formed in the cases of 70 and $105 \mathrm{MPa}$ squeeze pressure with the die preheated temperature and melt temperature of $225^{\circ} \mathrm{C}$ and $725^{\circ} \mathrm{C}$, respectively. 




FIGURE 14: Contour plot for YS versus die preheating temperature and pressure.

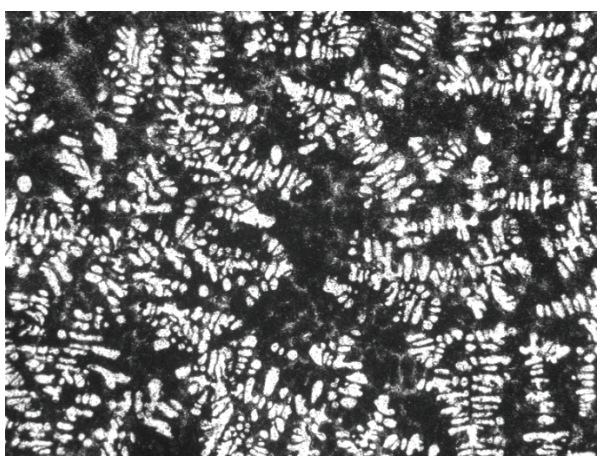

(a)

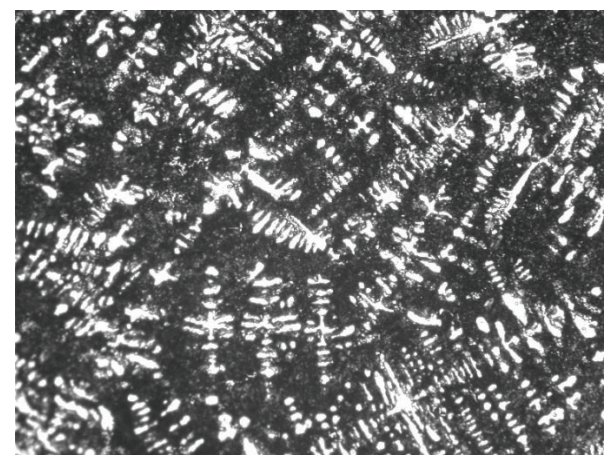

(b)

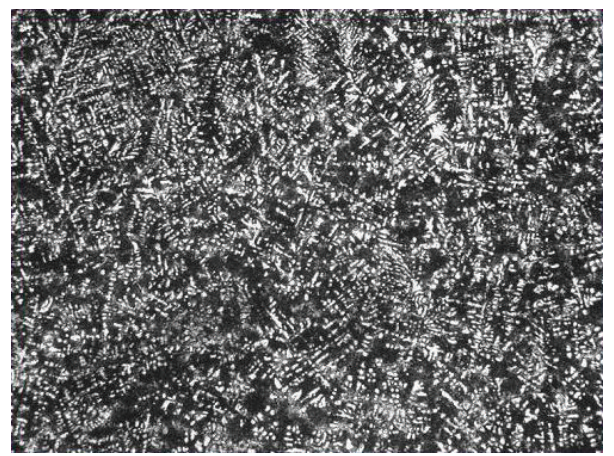

(c)

Figure 15: Microstructure at squeeze casting process: (a) $70 \mathrm{MPa}$, (b) $105 \mathrm{MPa}$, and (c) $140 \mathrm{MPa}$ of squeeze pressure (die preheated temperature and melt temperature are $225^{\circ} \mathrm{C}$ and $725^{\circ} \mathrm{C}$ which are fixed) at $100 \mathrm{x}$ magnification.

\section{Conclusion}

A413 aluminum alloy castings with different levels of squeeze pressure, die preheating temperature, and melt temperature were successfully fabricated by squeeze casting route. The influential variables and responses were systematically investigated as per full factorial design. Moreover the use of ANN to predict and ensure the experimental dataset and statistical tool to optimize the process variables were explored in this study. 40 different backpropagation neural network architectures are trained and tested based upon the correlation coefficient and mean error percentage, using the experimental data until an optimum architecture is identified. The following conclusions are evident from this experimental work. 
(i) Based on the number architectures that are used to train the ANN model using BP algorithm, the architecture (3-4-4-3) was in good agreement to that of the experimental values with the mean correlation coefficient of 0.96615 and mean error percentage of 0.92376 .

(ii) The developed model can provide beneficial data that can be predicted from the wide range of experimental database. Therefore time consuming experiments can be reduced and hence considerable savings in terms of cost and time could be obtained by using developed neural network model which serves as a boon for metal casting industry.

(iii) The results from the statistical tool reveal that optimal level of process variables for obtaining maximum mechanical behaviour (hardness, UTS, and yield strength) are as folllows:

squeeze pressure: $140 \mathrm{MPa}$,

die preheating temperature: $225^{\circ} \mathrm{C}$,

melt temperature: $725^{\circ} \mathrm{C}$.

(iv) From the ANOVA analysis, the most significant parameters were identified as squeeze pressure and die preheating temperature with percentage contribution of (70-78)\% and (15-18)\%, respectively, with $R$ Sq. value of $93.09 \%$.

\section{Conflict of Interests}

The authors declare that they have no conflict of interests regarding the publication of this paper.

\section{Acknowledgment}

The authors are thankful to Sri Krishna College of Engineering and Technology, Coimbatore, for providing research facilities to carry out this research work.

\section{References}

[1] J. R. Brown, Foseco Non-Ferrous Foundryman's Handbook, Butterworth Heinemann, 11th edition, 1994.

[2] G. E. Totten and D. S. Mackenzie, Hand Book of Aluminium, vol. 1 of Physical Metallurgy and Processes, Marcel Dekker, New York, NY, USA, 2003.

[3] R. M. Pillai, K. S. B. Kumar, and B. C. Pai, "A simple inexpensive technique for enhancing density and mechanical properties of Al-Si alloys," Journal of Materials Processing Technology, vol. 146, no. 3, pp. 338-348, 2004.

[4] H. Sevik and S. C. Kurnaz, "Properties of alumina particulate reinforced aluminum alloy produced by pressure die casting," Materials and Design, vol. 27, no. 8, pp. 676-683, 2006.

[5] H. Joardar, G. Sutradhar, and N. S. Das, "FEM simulation and experimental validation of cold forging behavior of LM6 base metal matrix composites," Journal of Minerals and Materials Characterization and Engineering, vol. 11, no. 10, pp. 989-994, 2012.
[6] H. Ye, "An overview of the development of Al-Si-alloy based material for engine applications," Journal of Materials Engineering and Performance, vol. 12, no. 3, pp. 288-297, 2003.

[7] T. M. Yue and G. A. Chadwick, "Principles and applications of squeeze casting," Metals and Materials, vol. 5, no. 1, pp. 6-12, 1989.

[8] H. Q. Hu, Principles of Metal Solidification, China Machine Press, Beijing, China, 2000.

[9] M. R. Ghomashchi and A. Vikhrov, "Squeeze casting: an overview," Journal of Materials Processing Technology, vol. 101, no. 1, pp. 1-9, 2000.

[10] J. R. Franklin and A. A. Das, "Squeeze casting-a review of the status," British Foundryman, vol. 77, no. 3, pp. 150-158, 1984.

[11] A. Fardi Ilkhchy, M. Jabbari, and P. Davami, "Effect of pressure on heat transfer coefficient at the metal/mold interface of A356 aluminum alloy," International Communications in Heat and Mass Transfer, vol. 39, no. 5, pp. 705-712, 2012.

[12] S. Rajagopal, "Squeeze casting: a review and update," Journal of Applied Metalworking, vol. 1, no. 4, pp. 3-14, 1981.

[13] A. Raji and R. H. Khan, "Effects of pouring temperature and squeeze pressure on $\mathrm{Al} 8 \% \mathrm{Si}$ alloy squeeze cast parts," $A U$ Journal of Technology, vol. 9, no. 4, pp. 229-237, 2006.

[14] E. Hajjari and M. Divandari, "An investigation on the microstructure and tensile properties of direct squeeze cast and gravity die cast 2024 wrought $\mathrm{Al}$ alloy," Materials and Design, vol. 29, no. 9, pp. 1685-1689, 2008.

[15] A. Kalkanli and S. Yilmaz, "Synthesis and characterization of aluminum alloy 7075 reinforced with silicon carbide particulates," Materials \& Design, vol. 29, no. 4, pp. 775-780, 2008.

[16] E. S. Kim, K. H. Lee, and Y. H. Moon, "A feasibility study of the partial squeeze and vacuum die casting process," Journal of Materials Processing Technology, vol. 105, no. 1-2, pp. 42-48, 2000.

[17] P. Balan, R. M. Pillai, K. G. Satyanarayana, and B. C. Pai, "The structure and properties of squeeze-cast eutectic Al-Si plates," International Journal of Science and Technology, vol. 4, no. 3, pp. 191-198, 1990.

[18] C. Velmurugan, V. Muthukumaran, K. Ragupathy, and S. Ragunath, "Modeling volume loss of heat treated Al 6061 composites using an artificial neural network," Procedia Materials Science, vol. 5, pp. 31-40, 2014.

[19] A. Canakci, S. Ozsahin, and T. Varol, "Prediction of effect of reinforcement Size and volume fraction on the abrasive wear properties of AA2014/B4Cp MMC's using artificial neural network," Arabian Journal for Science and Engineering, vol. 39, no. 8, pp. 6351-6361, 2014.

[20] D. B. Karunakar and G. L. Datta, "Prevention of defects in castings using back propagation neural networks," International Journal of Advanced Manufacturing Technology, vol. 39, no. 11-12, pp. 1111-1124, 2008.

[21] S. Malinov, W. Sha, and J. J. McKeown, "Modelling the correlation between processing parameters and properties in titanium alloys using artificial neural network," Computational Materials Science, vol. 21, no. 3, pp. 375-394, 2001.

[22] S. Ghosh, P. Sahoo, and G. Sutradhar, "Friction performance of Al-10\%SiCp reinforced metal matrix composites using Taguchi method," ISRN Tribology, vol. 2013, Article ID 386861, 9 pages, 2013.

[23] A. R. Ravikumar, K. S. Amirthagadeswaran, and P. Senthil, "Parametric optimization of squeeze cast AC2A-Ni Coated $\mathrm{SiC}_{p}$ composite using taguchi technique," Advances in Materials 
Science and Engineering, vol. 2014, Article ID 160519, 10 pages, 2014.

[24] P. Vijian and V. P. Arunachalam, "Optimization of squeeze casting process parameters using Taguchi analysis," International Journal of Advanced Manufacturing Technology, vol. 33, no. 1112, pp. 1122-1127, 2007.

[25] P. Vijian and V. P. Arunachalam, "Optimization of squeeze cast parameters of LM6 aluminium alloy for surface roughness using Taguchi method," Journal of Materials Processing Technology, vol. 180, no. 1-3, pp. 161-166, 2006.

[26] S. Ghosh, P. Sahoo, and G. Sutradhar, "Wear behaviour of AlSiCp metal matrix composites and optimization using taguchi method and grey relational analysis," Journal of Minerals and Materials Characterization and Engineering, vol. 11, no. 11, pp. 1085-1094, 2012.

[27] P. Senthil and K. S. Amirthagadeswaran, "Optimization of squeeze casting parameters for non-symmetrical AC2A aluminium alloy castings through Taguchi method," Journal of Mechanical Science and Technology, vol. 26, no. 4, pp. 1141-1147, 2012.

[28] P. Senthil and K. S. Amirthagadeswaran, "Experimental study and squeeze casting process optimization for high quality AC2A Aluminium alloy castings," Arabian Journal for Science and Engineering, vol. 39, no. 3, pp. 2215-2225, 2014.

[29] P. Vijian and V. P. Arunachalam, "Modelling and multi objective optimization of LM24 aluminium alloy squeeze cast process parameters using genetic algorithm," Journal of Materials Processing Technology, vol. 186, no. 1-3, pp. 82-86, 2007.

[30] E.-S. Lee and S.-Y. Baek, "A study on optimum grinding factors for aspheric convex surface micro-lens using design of experiments," International Journal of Machine Tools and Manufacture, vol. 47, no. 3-4, pp. 509-520, 2007.

[31] B. B. Mukharjee and S. V. Barai, "Assessment of the influence of Nano-Silica on the behavior of mortar using factorial design of experiments," Construction and Building Materials, vol. 68, pp. 416-425, 2014.

[32] B. H. Yan, C. C. Wang, H. M. Chow, and Y. C. Lin, "Feasibility study of rotary electrical discharge machining with ball burnishing for $\mathrm{Al}_{2} \mathrm{O}_{3} / 6061 \mathrm{Al}$ composite," International Journal of Machine Tools and Manufacture, vol. 40, no. 10, pp. 1403-1421, 2000.

[33] Y. R. Li, M. F. Shue, Y. C. Hsu, W. L. Lai, and J. J. Chen, "Application of factorial design methodology for optimization of transesterification reaction of microalgae lipids," Energy Procedia, vol. 52, pp. 377-382, 2014.

[34] C. Graciano and J. Mendes, "Elastic buckling of longitudinally stiffened patch loaded plate girders using factorial design," Journal of Constructional Steel Research, vol. 100, pp. 229-236, 2014.

[35] J. Javorsky, M. Franchetti, and H. Zhang, "Determining the optimal parameters of bonding polyvinylchloride to stainless steel in automotive applications with the use of full factorial design of experiment," CIRP Journal of Manufacturing Science and Technology, vol. 7, no. 2, pp. 151-158, 2014.

[36] ASTM International, "Standard specification for aluminumalloy castings produced by the squeeze casting, thixocast and rheocast semi-solid casting processes," Designation B969/ B969M-11, ASTM International, 2011.

[37] P. Sathiya, K. Panneerselvam, and R. Soundararajan, "Optimal design for laser beam butt welding process parameter using artificial neural networks and genetic algorithm for super austenitic stainless steel,' Optics and Laser Technology, vol. 44, no. 6, pp. 1905-1914, 2012.

[38] S. Sivasankaran, R. Narayanasamy, T. Ramesh, and M. Prabhakar, "Analysis of workability behavior of Al-SiC P/M composites using backpropagation neural network model and statistical technique," Computational Materials Science, vol. 47, no. 1, pp. 46-59, 2009.

[39] T. Varol, A. Canakci, and S. Ozsahin, "Artificial neural network modeling to effect of reinforcement properties on the physical and mechanical properties of Al2024- $\mathrm{B}_{4} \mathrm{C}$ composites produced by powder metallurgy,' Composites Part B: Engineering, vol. 54, no. 1, pp. 224-233, 2013.

[40] N. Altinkok and R. Koker, "Use of artificial neural network for prediction of physical properties and tensile strengths in particle reinforced alüminum matrix composites," Journal of Materials Science, vol. 40, no. 7, pp. 1767-1770, 2005.

[41] S. Sivasankaran, R. Narayanasamy, R. Jeyapaul, and C. Loganathan, "Modelling of wrinkling in deep drawing of different grades of annealed commercially pure aluminium sheets when drawn through a conical die using artificial neural network," Materials and Design, vol. 30, no. 8, pp. 3193-3205, 2009. 

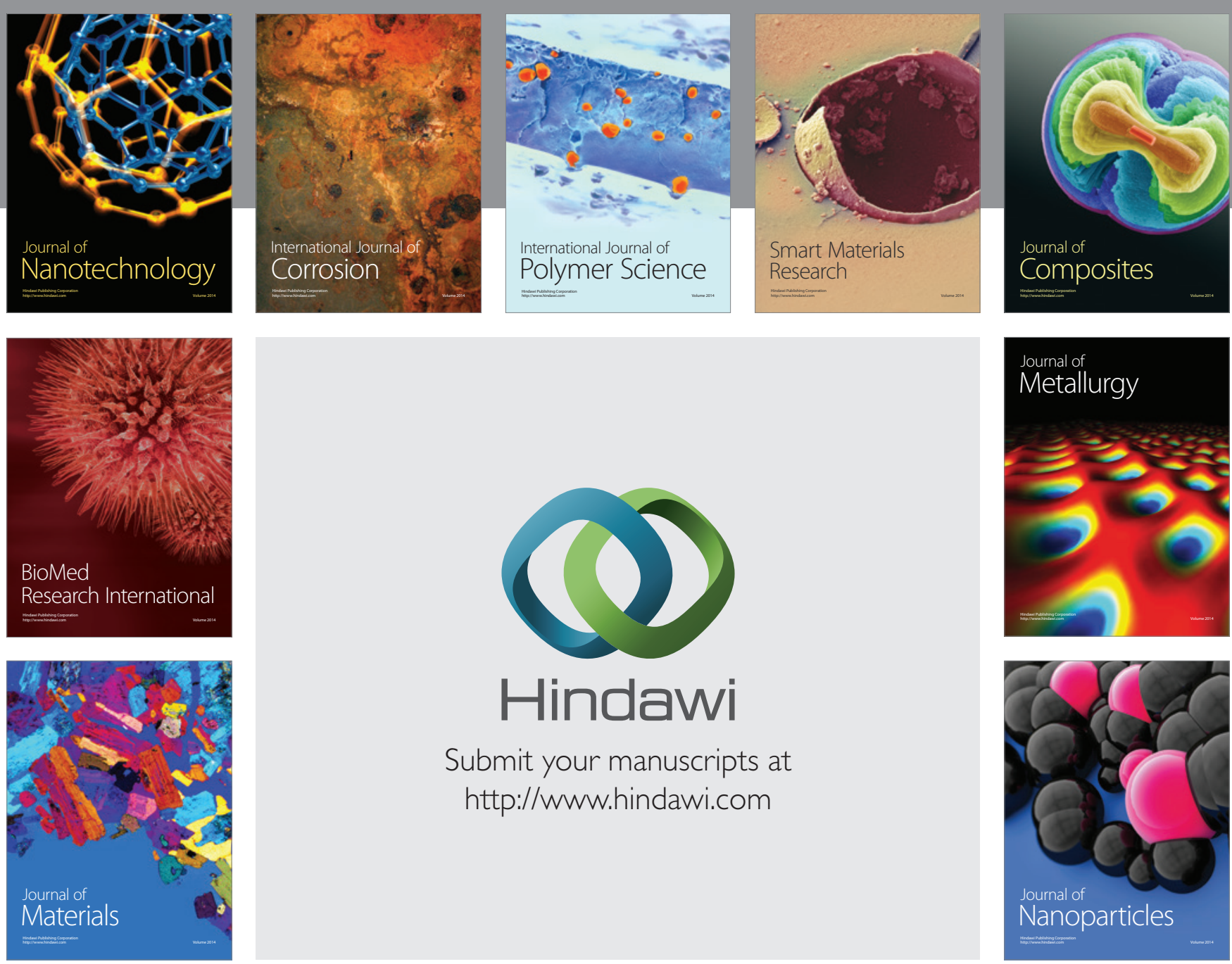

Submit your manuscripts at http://www.hindawi.com
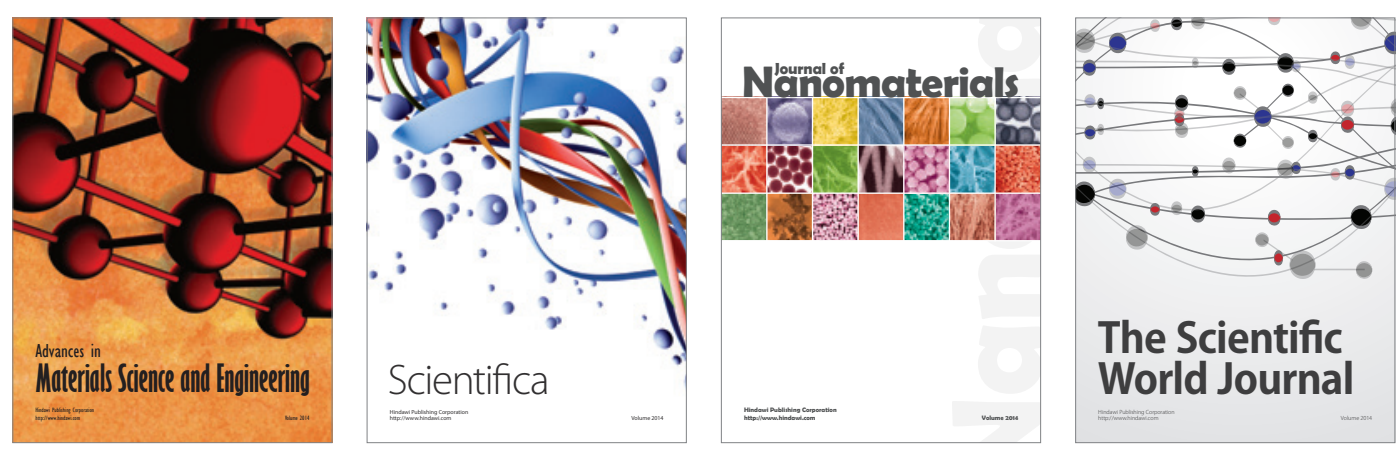

\section{The Scientific World Journal}
